\title{
Role of phosphodiesterase inhibitors in stent-related symptoms: a systematic review and meta-analysis
}

\author{
Zhongbao Zhou ${ }^{1,2}$ (1) $\cdot$ Zhenli Gao $^{2} \cdot$ Jitao Wu$^{2} \cdot$ Yuanshan Cui ${ }^{2}$
}

Received: 21 July 2019 / Accepted: 23 July 2019 / Published online: 29 July 2019

๑) Springer-Verlag GmbH Germany, part of Springer Nature 2019

Dear Editor in chief,

We read the study published by Sharma et al. [1] in the latest online issue of World Journal of Urology entitled "Role of phosphodiesterase inhibitors in stent-related symptoms: a systematic review and meta-analysis" with keen interest. This article was performed to analyze the efficacy of phosphodiesterase inhibitors in improving stent-related symptoms. From the methodology and the whole paper of meta-analysis, we found some problems that must be emphasized.

1. Only three studies fulfilled the methodological requirements, i.e., the population base of 280 patients is quite limited. The three randomized control trials collected for analysis in this study are with significant heterogeneity in study design, especially in comparison with different drugs (Aggarwal et al. [2]: tadalafil $5 \mathrm{mg}$ vs placebo vs tamsulosin $0.4 \mathrm{mg}$; Bhattar et al. [3]: tadalafil $5 \mathrm{mg}$ vs placebo vs silodosin $8 \mathrm{mg}$; Tharwat et al. [4]: sildenafil $50 \mathrm{mg}$ vs placebo), which made the data less comparable.

2. As stated in the original "Only random-effects model was adopted, as it would provide a more conservative estimate", this is an unreasonable study design on the basis of RevMan version 5.3.0 (Cochrane Collaboration, Oxford, UK) [5]. The indicator should be characterized as fixed-effects model if $P>0.05$, if not, a random-

This comment refers to the article available at https://doi. org/10.1007/s00345-019-02862-z.

Zhongbao Zhou

346894383@qq.com

1 School of Clinical Medicine, Binzhou Medical University, No. 346 Guanhai Road, Laishan District, Yantai 264000, Shandong, China

2 Department of Urology, The Affiliated Yantai Yuhuangding Hospital of Qingdao University, No. 20 East Yuhuangding Road, Yantai, Shandong, China effects model would be used. Therefore, the forest of some indicators should be redrawn for analysis.

3. For analgesic requirement, the meta-analysis of only one included study is unreasonable, strength of evidence (SOE) [6] should be defined as insufficient.

4. Sensitivity analysis usually not required if there are less than 10 trials. Formal assessment for publication bias should be included in the analysis.

5. There are typographical errors in the magazine of references 13 and 14.

\section{References}

1. Sharma G, Sharma AP, Mavuduru RS, Devana SK, Bora GS, Singh SK (2019) Role of phosphodiesterase inhibitors in stentrelated symptoms: a systematic review and meta-analysis. World J Urol. https://doi.org/10.1007/s00345-019-02862-Z

2. Aggarwal SP, Priyadarshi S, Tomar V, Yadav SS, Gangkak G, Vyas $\mathrm{N}$ et al (2015) A randomized controlled trial to compare the safety and efficacy of tadalafil and tamsulosin in relieving Double J stent related symptoms. Adv Urol 2015:592175

3. Bhattar R, Tomar V, Yadav SS, Dhakad DS (2018) Comparison of safety and efficacy of silodosin, solifenacin, tadalafil and their combinations in the treatment of double-J stent-related lower urinary system symptoms: a prospective randomized trial. Turk J Urol 44(3):228-238

4. Tharwat M, Elsaadany MM, Lashin AM, El-Nahas AR (2018) A randomized controlled trial evaluating sildenafil citrate in relieving ureteral stent-related symptoms. World J Urol 36(11):1877-1881

5. Higgins JP, Green S. Cochrane handbook for systematic reviews of interventions. version 5.3.0 [Internet]. The Cochrane Collaboration. Available from: www.cochrane-handbook.org. Accessed 18 July 2019

6. Berkman ND, Lohr KN, Ansari M, McDonagh M, Balk E, Whitlock $\mathrm{E}$ et al Grading the strength of a body of evidence when assessing health care interventions for the effective health care program of the Agency for Healthcare Research and Quality: an update. AHRQ Publication No. 13(14)-EHC130-EF. Agency for Healthcare Research and Quality, Rockville. www.effectivehealth care.ahrq.gov/reports/final.cfm. Accessed July 2019

Publisher's Note Springer Nature remains neutral with regard to jurisdictional claims in published maps and institutional affiliations. 